P-ISSN 2580 - 7781

E-ISSN 2615 - 3238

\title{
RESILIENSI DENGAN WORK ENGAGEMENT PADA KARYAWAN LAPANGAN
}

\section{RESILIENCE AND WORK ENGAGEMENT IN FIELD EMPLOYEES}

\author{
Yanto Prasetyo $^{1)}$, Hikmah Husniyah Farhanindya ${ }^{2}$ \\ ${ }^{1,2}$ Fakultas Psikologi, Universitas 17 Agustus 1945 Surabaya \\ ${ }^{1}$ Email : yanto-prasetyo@untag.ac.id
}

\begin{abstract}
ABSTRAK
Bekerja adalah jenis aktifitas yang dilakukan individu untuk mendapatkan uang. Seorang karyawan akan melakukan pekerjaannya dengan maksimal agar tidak tidak dipecat atau dikeluarkan dari suatu perusahaan. Work engagement pada diri karyawan sangat berpengaruh terhadap kemajuan perusahaan, apabila karyawan tidak memiliki work engagement tentu akan mengurangi target dan keuntungan yang didapatkan dari sebuah perusahaan. Penelitian ini bertujuan untuk mengetahui adanya hubungan antara resiliensi dengan work engagement pada karyawan lapangan PT. X. Penelitian ini menggunakan metode penelitian kuantitatif untuk menguji hipotesis penelitian. Subjek penelitian ini adalah karyawan lapangan PT. X. Jumlah subyek penelitian ini 49 karyawan dengan teknik pengambilan sampel yang digunakan adalah sampling incidental. Berdasarkan hasil perhitungan analisis data menggunakan teknik korelasi product moment diketahui koefisien $\left(\mathrm{r}_{\mathrm{xy}}\right)$ sebesar $=0,511$ pada taraf signifikan $\mathrm{p}=0,000 ;(\mathrm{p}<0,01)$, artinya ada hubungan positf dan sangat signifikan antara resiliensi dengan work engagement. Jadi dapat dikatakan semakin tinggi resiliensi, maka akan semakin tinggi juga work engagement pada karyawan, begitu juga sebaliknya. Sumbangan efektif dari variabel resiliensi terhadap work engagement sebesar $26.1 \%$.
\end{abstract}

Kata kunci : Resiliensi, Work engagement

\begin{abstract}
Work is a type of activity that individuals do to earn money. An employee will do his job to the maximum so as not to be fired or expelled from a company. Work engagement on employees is very influential on the progress of the company, if employees do not have work engagement, it will certainly reduce the targets and profits obtained from a company. This study aims to determine the relationship between resilience and work engagement in field employees of PT. X. This study uses quantitative research methods to test the research hypothesis. The subjects of this study were field employees of PT.X. The number of subjects in this study were 49 employees. The sampling technique used is incidental sampling. Based on the results of the calculation of data analysis with the product moment correlation technique, it is known that the coefficient ( $r x y)=0.511$ at a significant level of $p=0.000 ;(p<0.01)$, meaning that there is a positive and very significant relationship between resilience and work engagement. So it can be said that the higher the resilience, the higher the employee's work engagement, and vice versa. The effective contribution of the resilience variable to work engagement is $26.1 \%$.
\end{abstract}

Keywords: Resilience, Work engagement 
P-ISSN 2580 - 7781

E-ISSN 2615 - 3238

\section{PENDAHULUAN}

Perusahaan yang besar tentu tidak akan terlepas dari sumber daya manuisa dimana dapat dikatakan sebagai seorang karyawan dalam menggerakan proses bisnis dan menjalankan tugas atau urusan perusahaan. Agar perusahan tidak mengalami kerugian tentu membutuhkan karyawan yang mempunyai skill atau pengalaman dan berkompeten dibidangnya. Disemua perusahaan pasti memerlukan karyawan yang dapat bekerjasama antar individu maupun memiliki ketahanan ketika diberikan tekanan atau tugas dari atasan. Tidak jarang perusahaan merekrut tenaga kerja yang berasal dari luar kota sekitar perusahaan bahkan dari luar pulau terjauh hanya untuk mencari pekerja yang sesuai kompeten. Karyawan yang memiliki daya tahan lebih, merupakan bagian penting yang dimiliki seorang karyawan bagi perusahaannya agar tetap bisa berkompetitif. Seorang karyawan merupakan suatu elemen utama dari perusahaan daripada elemen lain seperti teknologi mesin, uang dan modal karena seorang karyawan atau individu yang akan menjadi penggerak lainnya.

Perusahaan (PT.X) adalah salah satu perusahaan BUMN yang besar dan bergerak pada jasa transportasi publik, khususnya jalur darat yang tersebar hampir di seluruh Indonesia. Sebagian pekerja memiliki tempat tinggal yang dekat dengan lingkungan kerjanya dan tidak sedikit pula banyak pekerja yang berasal dari luar kota dari tempat kerjanya, sehingga memerlukan waktu tempuh perjalanan yang lebih lama dan resiko saat melakukan perjalanan kerja. Kebijakan perusahaan yang melakukan mutasi kerja dianggap sebagai tuntutan dan profesionalitas perusahaan dalam menghadapi era modernisasi, belum lagi pada pekerja lapangan yang memiliki resiko tinggi terhadap kecelakaan kerja.

Ketika salah seorang kayawan (inisial A) baru saja di pindahkan tugas, si A selalu datang terlambat ketika baru libur bekerja yang membuat pekerjaan kurang memenuhi target. Berbeda dengan karyawan kedua (inisial B) yang merasa nyaman dan santai dengan tempat kerja yang baru. Pada kayawan ketiga (inisial C) lebih banyak melakukan izin dengan alasan kepentingan dan pada karyawan keempat (inisial D) yang lebih memilih untuk bertempat tinggal dekat pekerjaannya dari pada harus pulang pergi karena berbeda kota. Dari obersvasi 
P-ISSN 2580 - 7781

E-ISSN 2615 - 3238

dilapangan, didapatkan karyawan lebih memilih untuk berangkat bekerja lebih pagi dan bahkan ada yang bersama-sama untuk menyewa tempat tinggal di dekat tempat bekerja dan memilih untuk pulang kerumah dengan waktu dua kali dalam seminggu.

Karyawan di PT X ini sendiri rela melakukan perjalanan jauh dan berangkat lebih awal ke tempat kerja agar target kerja yang diberikan dapat terselesaikan dengan baik, bahkan sebagian karyawan lebih memilih untuk tinggal di kantor dan memilih pulang ke rumah sekitar seminggu dua kali, sehingga waktu untuk perusahaan lebih banyak. Menurut Bakker (2004) karyawan dengan work engagement dapat memperlihatkan sebuah kondisi dengan energi yang kuat, akan merasa apa yang dikerjakan memiliki arti berarti dan sangat signifikan, kondisi individu akan lebih banyak merasakan tugas yang diberikan sangat memiliki resiko, mempunyai daya berkonsentrasi yang cukup tinggi dan berantusias dalam melakukan pekerjaannya, berbeda dengan work engagement yang rendah pada karyawan lebih banyak merasakan pekerjaannya kurang menyukai dan tidak memiliki ketertarikan dari tugas yang telah diberikan, menjadikan individu malas dalam bekerja dan berimbas kepada menurunnya kualitas kerja atau minat karyawan dalam bekerja di perusahaan.

Sumber Daya Manusia sendiri tidak terlepas dari bagaimana pekerja atau pegawai tersebut melaksanakan tugasnya di dalam perusahaan, yang dimana dalam hal ini menyangkut tentang work engagement pekerja sendiri yang harus melakukan dengan profesional mungkin. Seorang karyawan akan berusaha untuk mencapai sebuah tujuan atau target, dilakukan dengan semangat dan antusias dalam bekerja. Merasa dirinya merupakan bagian penting dari perusahaan, sehingga karyawan akan memberikan waktu lebih untuk bekerja. Keinginan untuk bekerja secara terus menerus merupakan bagian dari work engagement.

Menurut penelitian yang dilakukan Marisa Reni dan Devi Jatmika (2018) karyawan yang engaged dengan pekerjaannya selalu memiliki pemikiran yang luas apabila suatu waktu tuntutan pekerjaan mengalami perubahan, memiliki level energi serta semangat yang tinggi, ketahanan secara mental dan tidak mudah lelah. Karyawan seharusnya memiliki keterikatan dengan perusahaan sehingga 
P-ISSN 2580 - 7781

E-ISSN 2615 - 3238

keterikatan yang dimiliki setiap karyawan akan berpengaruh terhadap produktivitas dalam bekerja. Hal ini sesuai dengan pendapat Vance (dalam Putri dkk, 2014) bahwa keterikatan yang dimiliki karyawan pada perusahaan akan membantu dalam meningkatkan kinerja perusahaan. Pada kenyataannya banyak karyawan tidak engaged, sehingga akan menimbulkan kerugian pada perusahaan. Hal ini sesuai riset yang dilakukan Gallup pada tahun 2016, di Indonesia hanya 8\% karyawan yang memiliki engaged dengan pekerjaannnya.

Work engagement meliputi beberapa aspek ialah emosi positif, memiliki keterlibatan penuh dalam melakukan pekerjaannya yang dikarakteristikkan dalam tiga dimensi utama yaitu semangat (vigor), dedikasi (dedication), serta penyerapan terhadap pekerjaan (absorption) (Bakker dalam Indrianti, 2012). Karyawan yang engaged akan berusaha menunjukkan performa terbaik mereka dalam menyelesaikan pekerjaannya. Hal ini terjadi karena karyawan mampu menikmati pekerjaan yang mereka lakukan sehingga pekerjaan akan terasa cepat selesai (Bakker dalam Indrianwati, 2012).

Terdapat beberapa faktor yang dapat mempengaruhi terbentuknya work engagement pada karyawan menurut Bakker dan Leiter dalam Anisa dan Cristiana, (2019) ialah : a) Tuntutan pekerjaan (job demand), tuntutan pekerjaan meliputi beberapa aspek antara lain lingkungan fisik, sosial, organisasi serta imbalan yang membutuhkan usaha baik fisik maupun psikologis; b) Sumber daya pekerjaan (job resources), yakni tuntutan pekerjaan yang merujuk pada aspek fisik, sosial, dan organisasi yang memungkinkan karyawan untuk mengurangi tuntutan pekerjaan serta mencapai target pekerjaan yang telah ditetapkan; c) Sumber daya perorangan (personal resources), yakni aspek-aspek yang terdapat pada diri individu yang berupa aspek fisik dan sosial berupa efikasi diri, locus of control dan self esteem untuk dalam menyelesaikan pekerjaan. Personal resources juga merupakan kemampuan individu dalam mengevaluasi diri secara positif yang berhubungan dengan resiliensi yang memberikan dampak pada lingkungan mereka bekerja.

Menjadi karyawan lapangan di perusahaan trasportasi publik memiliki beberapa tantangan dalam berkerja. Karyawan harus siap ditempatkan didaerah 
P-ISSN 2580 - 7781

E-ISSN 2615 - 3238

manapun meski jauh dari tempat tinggal asalnya, selain memerlukan waktu yang lama juga mengandung resiko. Selain itu, pekerjaan di lapangan membutuhkan ketahanan untuk terus melayani masyarakat tanpa mengeluh sedikit pun. Menghadapi keadaan seperti itu penting bagi seorang karyawan untuk memiliki resiliensi menghadapi situasi yang sulit seperti yang telah dijabarkan sebelumnya.

Hubungan antara kondisi psikologis karyawan pekerjaannya memegang peranan yang sangat penting khususnya pada sektor pekerjaan berhubungan dengan informasi dan pelayanan (Bakker dalam Indrianti, 2012). Suatu organisasi atau perusahaan tidak lagi hanya mencari calon karyawan yang memiliki kemampuan dibatas rata-rata, namun juga mencari calon pegawai yang kemampuan dalam diri guna ikut terlibat secara penuh dalam pekerjaan serta memiliki komitmen yang tinggi terhadap standar kualitas kinerja (Bakker dalam Indirianti, 2012). Hal ini sering disebut dengan istilah work engagement. Berdasarkan pendapat diatas mengenai faktor-faktor yang dapat mempengaruhi work engagement, dapat disimpulkan bahwa aspek psikolog individu dapat berpengaruh dalam munculnya work engagement dalam hal ini berkaitan dengan resiliensi.

Menurut Reivich. K dan Shatte. A (2002) resiliensi ialah kemampuan seorang individu dalam mengatasi serta mampu beradaptasi terhadap keadaan yang berat yang terjadi dalam kehidupan, individu juga memiliki kemampuan bertahan dalam tekanan dan mampu menghadapi kesengsaraan (adversity) atau trauma yang dialami dalam kehidupannya. Seseorang yang memiliki resiliensi yang baik mereka tidak akan mudah menyerah dalam menghadapi situasi yang penuh tekanan, serta terus berusahan beradaptasi dengan lingkungan dan bangkit dari situasi yang tidak menyenangkan ke situasi yang lebih baik. Sedangkan menurut Siebert (2005) dalam buku The Resiliency Advantage mengungkapkan resiliensi yakni kemampuan individu dalam mengelola dan menjaga kesehatan emosi saat berada dalam keadaan penuh tekanan dan mampu bangkit dari keterpurukan serta menjalankan hidup dengan hal yang positif.

Menurut Menurut Wagnild dan Young (1993) Resiliensi adalah sebuah kekuatan emosional yang digunakan untuk menggambarkan orang-orang 
P-ISSN 2580 - 7781

E-ISSN 2615 - 3238

memunculkan keberanian serta kemampuan adaptasi ditengah kesulitan dan masalah hidup. Wagnild dan Young (1993) menggambarkan dimensi resiliensi menjadi 5 yaitu :

\section{Equanimity}

Equanimity dicirikan dengan memiliki pandangan yang seimbang mengenai kehidupan. Seseorang yang memiliki equanimity bahkan memandang bahwa hidup adakalanya berada diatas dan berada dibawah, atau bahagia dan sulit.

\section{Perseverance}

Perseverance memiliki semangat untuk terus bertahan walaupun berada dalam kesulitan. Seseorang yang memiliki perseverance bila mengalami kesulitan atau keputusasaan akan tetapi menginginkan untuk melanjutkan perjuangannya dan melaksanakannya dengan disiplin.

\section{Self Reliant}

Self reliant adalah keyakinan akan kemampuan dalam diri dengan segala keterbatasan di dalam dirinya. Seseorang yang memiliki self reliant, maka ia percaya pada diri dan kemampuan yang dimilikinya.

\section{Meaningfulness}

Meaningfulness memiliki tujuan dan makna hidup. Seseorang yang memiliki meaningfulness akan melakukan berbagai hal dengan berdasarkan tujuan dan memberi nilai yang bermakna dalam hidupnya.

\section{Existentialialoneness}

Existentialialoneness memiliki keyakinan bahwasanya setiap individu memiliki keunikan hidup masing-masing. Seseorang yang Existentialialoneness maka dia akan merasa bebas dan unik atau berbedah dengan lainnya.

Berbagai uraian diatas hipotesis pada penelitian ini adalah adanya hubungan antara resiliensi dengan work engagement pada karyawan lapangan PT. X. Semakin tinggi resiliensi, maka akan meningkatkan work engagement yang tinggi pula pada diri karyawannya. Namun sebaliknya semakin rendah resiliensi, maka semakin renah pula work engagement pada karyawan. Sehingga penelitian ini bertujuan untuk mengetahui resiliensi dengan work engagement karyawan lapangan PT X. 
P-ISSN 2580 - 7781

E-ISSN 2615 - 3238

\section{METODE PENELITIAN}

Penelitian ini menggunakan metode penelitian kuantitatif. Pada penelitian ini, populasi yang diambil oleh peneliti adalah PT. X. Berdasarkan subjek yang didapatkan dalam penelitian ini yaitu 49 subyek. Metode pengambilan sampel menggunakan sampling insidental atau kebetulan yang berjumpa dengan peneliti bisa digunakan untuk sample bila sampel dinilai individu yang secara kebetulan ditemui dan dianggap sesuai sebagai sumber data. Instrument yang digunakan pada penelitian ini berupa kuesioner yang berisi pertanyaan seputar resiliensi dan work engagement pada karyawan. Pengumpulan data dalam penelitian ini menggunakan work engagement dengan skala UWES (Utrecht Work Engagement Scale) yang berisi 17 item dari aspek vigor (semangat), dedication (dedikasi), absorption (penyerapan). Skala kedua yaitu resiliensi dalam penelitian ini, menggunakan Resilience Scale ${ }^{\mathrm{TM}}$ (RS $^{\mathrm{TM}}$ ) yang berdasarkan teori Wagnild dan Young (1993) terdiri dari 25 item yang mempresentasikan lima karakteristik resiliensi.

\section{HASIL DAN PEMBAHASAN}

\section{Uji Normalitas}

Berdasarkan hasil uji normalitas sebaran untuk variabel resiliensi menggunakan Kolmogrov-Smirnov diperoleh nilai statistic sebesar 0.075 dengan signifikansi $\mathrm{p}=0,200<0,05$. Variabel work engagement diperoleh nilai statistic sebesar 0.091 dengan signifikansi $\mathrm{p}=0,200<0,05$. Artinya sebaran data variabel resiliensi dan work engagement terdistribusi normal.

Tabel 1. Hasil uji Normalitas Kolmogorov Smirnov

\begin{tabular}{cccc}
\hline Variabel & $\mathrm{Z}$ & $\mathrm{p}$ & Keterangan \\
\hline Resiliensi & 0.075 & 0.200 & Terdistribusi Normal \\
Work & 0.091 & 0.200 & Terdistribusi Normal \\
Engagement & & &
\end{tabular}

Sumber : SPSS Versi 22.00 for windows

\section{Uji Linieritas}

Hasil uji linieritas antara variabel resiliensi (X) dengan variabel work engagement $(\mathrm{Y})$ diperoleh nilai skor sebesar $\mathrm{f}=16.632$ dengan signifikansi $\mathrm{p}=$ 
P-ISSN 2580 - 7781

E-ISSN 2615 - 3238

$0,000<0,05$. Artinya terdapat hubungan yang linier antara resiliensi dengan variabel work engagement.

Tabel 2. Hasil Uji Lineritas

\begin{tabular}{lcccc}
\hline \multicolumn{1}{c}{ Variabel } & R Square & $\mathrm{F}$ & $\mathrm{P}$ & Keterangan \\
\hline resiliensi & 0.261 & 16.632 & $0.000(\mathrm{p}<0.05)$ & $\begin{array}{c}\text { Terdapat Hubungan yang } \\
\text { linear }\end{array}$ \\
(X) dengan & & & & \\
variabel & & & \\
work \\
engagemen \\
$t(\mathrm{Y})$
\end{tabular}

\section{Uji Hipotesis}

Berdasarkan hasil uji Korelasi product moment dengan bantuan Statistical Package for the Social Sciences (SPSS) versi 22.00 for Windows menunjukkan hasil nilai koefisiensi $\operatorname{rxy}=0.511$ dengan $\mathrm{p}=0.000(\mathrm{p}<0.01)$ yang artinya terdapat hubungan positif yang sangat signifikan antara resiliensi dan work engagement. Berdasarkan hasil tersebut hipotesis dalam penelitian ini diterima. Berdasarkan nilai koefisien R2 pada hasil uji linieritas hubungan dapat diperoleh nilai R2 $=0.261$ yang berarti terdapat sumbangan efektif dari variabel resiliensi terhadap work engagement sebesar $26.1 \%$.

Tabel 3. Korelasi Product Moment

\begin{tabular}{llc}
\hline \multirow{2}{*}{ Resiliensi } & \multicolumn{2}{c}{ Work engagement } \\
\cline { 2 - 3 } & Pearson & 0.511 \\
& Correlation & 0.00 \\
& p-value & 0 \\
\hline
\end{tabular}

\section{PEMBAHASAN}

Berdasarkan hasil penelitian dengan koefisien korelasi sebesar $\left(\mathrm{r}_{\mathrm{xy}}\right)=0,511$ dengan taraf signifikansi $(\mathrm{p})=0,000(\mathrm{p}<0,01)$ menunjukan bahwa terdapat hubungan positif dan sangat signifikan antara resiliensi dengan work engagement. Artinya semakin tinggi resiliensi maka akan semakin tinggi pula work engagement yang dimiliki pleh karyawan lapangan PT. X, dan sebaliknya semakin rendah resiliensi maka akan semakin rendah pula work engagement yang dimiliki oleh karyawan lapangan PT. X. Dapat dinyatakan hasil hipotesis dari 
P-ISSN 2580 - 7781

E-ISSN $2615-3238$

penelitian ini berbunyi "terdapat hubungan positif antara resiliensi dengan work engagement" dapat diterima.

Pentingnya karyawan memiliki work engagement sangat berpengaruh untuk menunjang proses bisnis di suatu perusahaan. Sebab jika karyawan itu tidak memiliki work engagement yang tinggi akan menimbulkan gangguan dalam pengelolaan sumber daya manusia di perusahaan dan pada akhirnya target yang ditetapkan oleh perusahaan menjadi tidak terpenuhi sehingga menimbulkan kerugian terhadap perusahaan. Pada dasarnya setiap perusahaan menginginkan karyawannya memiliki work engagement dalam bekerja sehingga perusahaan tidak akan dihadapkan hanya pada persoalan-persoalan mencari karyawan lagi. Sebab jika karyawan itu mudah resign dari perusahaan tentu mengakibatkan terganggunya proses bisnis.

Menurut Schaufeli dan Bakker (2003) ada karakteristik pada work engagement karyawan, dimana pertama adalah vigour atau energi, adalah sebuah kekuatan yang ada pada karyawan yang dapat dikeluarkan, tingginya keinginan agar menyelesaikan usaha atau menghadapi kesulitan ditunjukkan dengan ketekuannya. Dilakukan dengan bersungguh-sungguh mengerjakan pekerjaan dan memiliki ketahanan kuat menyelesaikan kendala. Dimensi kedua dedication (dedikasi) ialah rasa antusias, menginspirasikan, dan rasa bangga; identifikasi yang kuat pada pekerjaannya. Dimensi yang ketiga adalah absorption (penyerapan) yaitu selalu berkonsentrasi penuh dan selalu fokus dengan pekerjaannya. Absorption sendiri mempunyai ciri karyawan akan melakukan pekerjaanya secara penuh sadar dan berkonsentrasi tinggi, sehingga menjadikan karyawan akan merasa waktu berlalu begitu cepat serta keluar dari pekerjaannya begitu sulit.

Work engagement selalu memiliki keterkaitan dengan segala jenis tantangan yang ada pada pekerjaan di perusahaan. Karyawan akan dapat mengungkap nilai kemampuan pada diri karyawan dan ketika akan menyelesaikan sebuah kendala atau masalah, berkaitan pada karyawan lain dan juga menumbuhkan solusi atau alternatif yang berinovasi. Faktor yang dapat meningkatkan work engagement salah satunya ialah resiliensi. Resiliensi adalah kemampuan individu dalam 
P-ISSN 2580 - 7781

E-ISSN 2615 - 3238

mengelola emosi, tidak mudah menyerah dalam menghadapi situasi yang penuh tekanan, serta terus berusaha beradaptasi dan berusaha bangkit dari situasi yang tidak menyenangkan ke situasi yang lebih baik. Resiliensi dicirikan dengan keadaan individu yang tekun dalam menyelesaikan tugas, karyawan percaya dengan kemampuan yang dia miliki serta karyawan akan berusaha mencari jalan keluar atas permasalahan yang dihadapi dan tidak meninggalkan tanggung jawab yang telah perusahaan berikan kepadanya. Begitupun sebaliknya karyawan yang memiliki resiliensi yang rendah maka karyawan akan menunjukan sikap yang tidak optimis, sulit beradaptasi terhadap perubahan, mudah menyerah.

Hasil penelitian yang sudah dilakukan mendapatkan hasil dengan sumbangan efektif variabel resiliensi terhadap keterikatan kerja sebesar $26.1 \%$. Hal ini menunjukkan bahwa resiliensi sebagai salah satu faktor yang memepengaruhi work engagement. Adapun sisa persentase sebesar 48,4\% menunjukkan bahwa ada faktor lain yang dapat mempengaruhi variabel work engagement, sebagaimana yang dijelaskan pada bab sebelumnya bahwa faktor faktor yang dapat mempengaruhi keterikatan kerja yakni job demand, job resource dan personal resource seperti kepemimpinan, efikasi diri, dukungan sosial dan lain sebagainya.

Didukung dengan penelitian oleh Anisa Putri Sari dan Christiana Hari Soetjiningsih (2019) dengan judul "Hubungan Resiliensi dengan Work Engagement pada Karyawan Produksi Bagian Cutting PT. Argo Manunggal Triasta” terdapat hubungan positif yang signifikan antara dengan keterikatan kerja pada perusahan yang diteliti. Hal ini dapat disimpulkan bahwa resiliensi yang tinggi dapat berdampak pada keterikatan kerja yang dimiliki karyawan, begitu sebaliknya resiliensi yang rendah akan membuat karyawan menjadi tidak memiliki keterikatan dengan pekerjaanya. Maka penelitian ini mendukung penelitian yang dilakukan Marisa Reni Santoso dan Devi Jatmika. Hal ini sesuai dengan penelitian yang dilakukan oleh Marisa Reni Santoso dan Devi Jatmika (2017) dengan judul "Hubungan Resiliensi dengan Work Engagement pada Agen Asuransi”. Mengungkapkan bahwa terdapat hubungan positif antara resiliensi dengan keterikatan kerja pada perusahan yang diteliti. 
P-ISSN 2580 - 7781

E-ISSN 2615 - 3238

\section{KESIMPULAN DAN SARAN}

\section{Kesimpulan}

Penelitian ini bertujuan untuk mengetahui adakah hubungan antara resiliensi dengan work engagement pada karyawan lapangan. Resiliensi ialah kemampuan yang dimiliki individu dalam mengelola emosi, kemampuan bertahan, tidak mudah menyerah dalam menghadapi situasi yang dipenuhi tekanan, serta terus berusaha beradaptasi dengan lingkungan dan bangkit dari situasi yang tidak menyenangkan ke situasi yang lebih baik. Sedangkan work engagement suatu perasaan terikat terhadap pekerjaan yang akan berdampak pada diri karyawan dan perusahaan seperti halnya karyawan akan menunjukan kemampuan terbaiknya dalam menyelesaikan pekerjan serta memberikan kompetensi yang dimilikinya guna tercapainya tujuan perusahaan. Subyek penelitian ini adalah karyawan lapangan di PT. X. Pengambilan data dilakukan dengan menggunakan dua skala yakni skala resiliensi dengan work engagement. Analisis data yang digunakan yakni menggunakan metode analisa data product moment.

Hasil penelitian ini menunjukkan bahwa terdapat hubungan antara resiliesnsi dengan work engagement $r_{x y}=0.511$ dengan signifikansi $(p)=0,000(p$ $<0,01)$. Dapat ditarik kesimpulan bahwa terdapat hubungan yang positif dan sangat signifikani antara resiliensi dengan work engagement pada karyawan lapangan PT. X. Dengan demikian berarti hipotesis dalam penelitian ini diterima, artinya semakin tinggi resiliensi, maka semakin tinggi pula work engagement pada karyawan lapangan.

\section{Saran}

Berdasarkan uraian diatas dan hasil analisis data penelitian yang telah diperoleh maka dapat berbagai saran dari beberapa pihak sebagai berikut :

1. Bagi instansi

a. Menumbuhkan work engagement pada karyawan dengan memberikan pelatihan.

b. Harapan untuk instansi yang terkait dapat menggunakan resiliensi sebagai salah satu indikator guna menyeleksi karyawan baru yang akan bekerja di perusahaan dengan tuntutan dan tugas yang ada. 
P-ISSN 2580 - 7781

E-ISSN 2615 - 3238

2. Bagi peneliti lain

a. Diharapkan untuk peneliti selanjutnya dapat mengungkap variabel lain yang dapat mempengaruhi work engagement dengan faktor-faktor lainnya yang memiliki hubungan ataupun dapat meningkatkan keterikatan kerja seperti: dukungan sosial, kepemimpinan, iklim organisasi, efikasi diri.

b. Diharapkan untuk peneliti selanjutnya dapat memperluas tempat penelitian sehingga sebaran data semakin merata dan mewakili populasi.

\section{DAFTAR PUSTAKA}

Bakker, A. B. 2011. An evidence-based model of work engagement. Current directions in psychological science, 20(4), 265-269.

Indrianti, R.. 2012. Hubungan Antara Modal Psikologis dengan Keterikatan Kerja pada Perawat di Instalasi Rawat Inap Rumah Sakit Jiwa Menur Surabaya. Jurnal Psikologi Indusri dan Organisasi, 1(2), 110-115.

Reivich, K., dan Shatté, A. 2002. The resilience factor: 7 essential skills for overcoming life's inevitable obstacles. Broadway books.

Santoso, M. R., \& Jatmika, D. 2017. Hubungan Resiliensi dengan Work Engagement Pada Agen Asuransi PT X. Ecopsy, 4(2), 117-123.

Sari, A. P., \& Soetjiningsih, C. H. 2019. Hubungan Resiliensi Dengan Work Engagement Pada Karyawan Produksi Bagian Cutting Pt. Argo Manunggal Triasta. Jurnal Psikohumanika, 11(1), 33-44.

Scaufeli \& Bakker. 2004. Utrech Work Engagement Scale (UWES).1-41

Schaufeli, W. B. 2006. The Measurement of Work Engagement With a Short Questionnaire : A Cross- National Study. Journal of Educational and Psychological Measurement, 66, 701-716

Siebert, A. 2005. The Resiliency Advantage : Master Change, Thrive Under Pressure, and Bounce Back from Setbacks. California: Berrett- Koehler Publishers, Inc.

Wagnild, G. M., \& Young, H. M. 1993. Development and psychometric evaluation of the Resilience Scale. Journal of Nursing Measurement, $1(2), 165-178$.

Young, W. 1993. Development and Psychometric Evaluation of the Resilience Scale. Journal of Nursing Measurement. Springer Publishing Company, $1(2)$. 